\title{
Humoral Immune Response And Midgut Histopatholical Changes In Grasshopper Schistocerca Gregaria Fed On Four Different Plants And Infected With Bacillus Thuringiensis
}

\author{
Emad, M.S. Barakat ${ }^{1}$; Mona F. Abd-EL Aziz ${ }^{2 *}$; Olfat M. El-Monairy ${ }^{2}$; Nehad \\ M. El-Barky ${ }^{2}$ And Heba F. Abd-El Khalek ${ }^{2}$ \\ ${ }^{I}$ Entomology Department - Faculty Of Science-Ain Shams University \\ ${ }^{2}$ Entomology Department - Faculty Of Science-Benha University
}

\begin{abstract}
The present study investigated the effect of dietary changes on differential and total haemocyte counts (THCs) and midgut histopathologiocal changes of S. gregaria injected with Bacillus thuringiensis israelensis (Bti). THCs of Bti-injected adults significantly decreased in all insects fed on all experimental plants. In Bti-injected locusts, prohaemocytes (PRs) percent decreased in insects fed on grass and quietly disappeared in other treatments. plasmatocytes (PLS) percent increased, while the granulocytes (GRs) decreased in all tested insects fed on sorghum, sesban, grass and clover than those of the control. The percentages of oenocytoids (OEs) increased in all treatments except in insect fed on sesaban. The results indicated that insects fed on clover had the highest number of haemocytes, while those fed on grass had the lowest number. Certain pathological symptoms in the midgut of Bti treated adults were observed after $48 \mathrm{hr}$ post injection, such as (1) disorganisation, disintegration and vacuolization of epithelial cells, (2) lysis of the basement membrane and surrounding muscles and (3) detachment of microvilli from epithelial cells. The most deformed group to Bti was grass fed locust. Subsequently, the host plant could be a major factor that affect on the response of herbivorous insects to pathogens.
\end{abstract}

Keywords: Bti; haemocytes; histopathology; immunology; midgut ; Schistocerca gregaria

\section{Introduction}

The desert locust, $S$. gregaria (Forskal), is the most dangerous generalist insect herbivore species. The host quality can be weakened or strengthened immune responses of insects to pathogens (Lampert, 2012). The host plant can alter the immune function of herbivorous insects by inducing a difference in their susceptibility to the pathogens (Vogelweith et al., 2011). When phytophagous insects are reared on host plants with differing nutritional qualities, it is probable that the baseline defense response would also differ. Invasion by a pathogen can induce the cellular and humoral defense response to higher levels (Gillespie et al., 1997). Poor nutritional quality may effect in the investment in immune factors resulting in physiological changes that may influence the entry of pathogens via the mid-gut or the cuticle (Shikano et al., 2010). Plymale et al. (2008) showed that diet alters the structure of the peritrophic matrix (PM) in Lepidoptera larvae, this change can have an important role in control of pathogen infection. In addition, hemocytes have a key role in the cellular component of immune defense (Strand, 2008). Fewer studies have addressed the influence of plant quality on insect susceptibility more indirectly either before pathogen exposure or after infection. Accurate methods to measure immune response in the presence and absence of pathogens are necessary to determine whether susceptibility to these natural enemies is reduced or increased by host plant traits (Lampert, 2012).

Based on the success of Bti as a bio-control agent in the Egyptian fields against Lepidoptera and Diptera, the present study deals with the interactions among herbivorous insect (S. gregaria), host plant, and pathogen (Bti). We studied two categories: i) Differential and total haemocyte counts ii) Midgut histopathologiocal changes. The expected results may lead to understanding of the physiology of infected insects, and hence encourage the using of $\mathrm{Bt}$ agents this dangerous pest.

\subsection{Insect rearing:}

\section{Materials and Methods}

The desert locust, S. gregaria (Forskal), was obtained from Plant Protection Research Institute, Agricultural Research Center, Egypt, reared for several generations and had shown no infectious diseases. Locusts were reared according to the method that was previously described by Huxham et al. (1989). Insects were divided into four groups; two groups were reared on sorghum (Sorghum bicolor) or sesban (Sesbania sesban) in summer, while in winter the other two groups were reared on grass (Andropogon citratus) or clover (Trifolium alexandrinum). 


\subsection{BTi injection technique:}

Bti (1600 IU/mg, wettable powder) was produced from the Agricultural Genetic Engineering Research Institute (AGERI) at the Ministry of Agriculture, Egypt. Four groups of $S$. gregaria adults (2-4 days) fed on sorghum, sesban, grass or clover were injected with Bti $\operatorname{LD}_{20}\left(3.1 \times 10^{4}, 1.37 \times 10^{5}, 1 \times 10^{5}\right.$, and $1.1 \times 10^{5}$ Cells $\left./ \mathrm{ml}\right)$ for grass, clover, sorghum and sesban, respectively according to Barakat et al. (2013). $10 \mu \mathrm{l}$ were injected into each insect. Control insects were injected only with equivalent volumes of sterile distilled water.

\subsection{Differential haemocyte counts (DHCs):}

After $48 \mathrm{hr}$ of Bti injection the haemolymph samples were withdrawn from the coxal corium according to Hoffmann (1980). Haemocytes (blood films) were stained by Giemsa stain and examined by light microscopy. The haemocytes are classified according to the classification scheme of Hoffmann (1969). Various haemocytes were differentially counted by examining approximately 100 cells per slide. 10 slides prepared from 10 locusts / count. The percentages of haemocyte types were calculated by the formula:

$\%=\frac{\text { Number of each haemocyte type X100 }}{\text { Total number of haemocytes examined }}$

\subsection{Total haemocyte counts (THCs):}

The oozed haemolymph was collected directly into Thoma- white blood cell diluting pipette to the mark 0.5. Diluting solution ( $\mathrm{NaCl}-4.65 \mathrm{~g}, \mathrm{KCl}-0.15 \mathrm{~g}, \mathrm{CaCl} 2-0.11 \mathrm{~g}$, crystal violet- $0.05 \mathrm{~g}$ and acetic acid$1.25 \mathrm{ml} /$ liter distilled water) was taken up to the mark 11 on the pipette (dilution is 20). The mixture was dispensed to both chambers of the counting slide (the chamber depth is $1.0 \mathrm{~mm}$ ) and the total number of cells were counted according to the formula of Jones (1962):

Haemocytes in $1 \mathrm{~mm}$ squares $\mathrm{X}$ dilution $\mathrm{X}$ depth of chamber

Number of $1 \mathrm{~mm}$ squares counted

\subsection{Midgut histopathological studies:}

Adults (2-4 days) fed on four tested plants in normal state or injected with $\mathrm{LD}_{20} B t i$ were dissected from the ventral side to extract the midguts then washed rapidly in saline solution $0.9 \% \mathrm{Na} \mathrm{Cl}$ (Merck), and then intensely immersed in distilled water. histological analysis were carried out according to Disbrey and Rick (1970). The samples were fixed in Bouin's solution. Dehydration of samples was carried out through putting the samples in ascending series of ethyl alcohol (70\%, to 100\%) and embedded in paraffin, the samples were sliced in 5 and $10 \mu \mathrm{m}$ in thickness sections and stained with hematoxylin-eosin stain. Morphological changes of the midgut cell structure and organization were observed by light microscopy and compared to the tissues taken from the control group.

\subsection{Statistical analysis:}

Data of the experiments were analyzed by using the statistical computer application origin program, Version 7.0. Analysis of one-way ANOVA was made on the data obtained, and Student's $t$-test was used for testing the significance differences. The level of significance for each experiment was set at $\mathrm{P}<0.05$ or $\mathrm{P}<0.01$.

\section{Results}

The differential haemocyte counts of adults fed on four different experimental plants varied considerably as shown in Table (1). The percentages of different haemocyte types of adults injected with $\mathrm{LC}_{20}$ $B t i$ were presented in the same table. The percentage of PRs decreased in treated insects fed on grass $(3.20 \%)$ compared to the control $(14.50 \%)$. PRs disappeared in treated insects fed on sorghum, sesban and clover. The results also recorded that the highest number of PLs was recorded in treated insects fed on clover $(75.10 \%)$ while the lowest number was recorded in treated insects fed on grass $(65.9 \%)$ than other treatments. GRs percent decreased when treated insects fed on sorghum, sesban, grass or clover compared with control insects. The percentages of OEs increased in all treatments except in insect fed on sesaban compared with control groub.

Figure (1) showed the effects of $\mathrm{LC}_{20}$ of Bti on $\mathrm{THC}_{\mathrm{S}}$ of $S$. gregaria adults fed on experimental plants at $48 \mathrm{hr}$ post-injection. The THC values showed a significant decrease $(\mathrm{P}<0.05)$ with all treated adults fed on clover, sorghum or sesban $\left(9413 \pm 71.10,9260 \pm 76.103\right.$, or $9225 \pm 96.91$ cells $/ \mathrm{mm}^{3}$, respectively) compared with controls $\left(9625 \pm 45.49,9580 \pm 42.95\right.$ and $9805 \pm 43.75$ cells $/ \mathrm{mm}^{3}$, respectively), except insect fed on grass $\left(8975 \pm 39.58 \mathrm{cells} / \mathrm{mm}^{3}\right)$ which showed highly significance decrease at $\mathrm{P}<0.01$ compared with the control $\left(9425 \pm 80.02\right.$ cells $\left./ \mathrm{mm}^{3}\right)$.

Figures (2-5A) describe the anterior part of the normal midgut of the desert locust adults fed on grass, sorghum, sesban, or clover, respectively. The midgut consists of 4 main parts: a longitudinal muscles layer followed by circular muscles (Mu), a basal membrane (BM), an epithelial layer (Ep) and a single uniform layer of cells with apical microvilli (Mi). The epithelium is composed of columnar cells, with a great number of small 
undifferentiated groups of regenerative cells (RC) scattered along the basal portion of the epithelium. A single uniform layer of cells with apical microvillus constitutes the absorbing part which is protected by a thin peritrophic membrane. Insects fed on grass (Fig.2A) showed more delicate microvilli than insects fed on sorghum, sesban or clover (Fig. 3-5A) which were not different from each other.

Histopathological changes in the midgut of $S$. gregaria adults fed on experimental plants and treated with $\mathrm{LC}_{20}$ of $B t i$ at $48 \mathrm{hrs}$ post injection revealed certain pathological symptom. Adult injected with $B t i$ and fed on grass were the most susceptible group and showed obvious changes in the mid-gut. Epithelial cells appeared to be completely disorganised and disintegrated downwardly. Some of these cells were sloughed in the gut lumen and destroyed in some instances. The basement membrane and surrounding muscles seemed to be destroyed. Vaculation appeared in regenerative cells (Fig. 3B).

According to pathological symptoms in insects fed on sorghum, there was fading of cellular boundaries and slight vaculation (Fig. 4B). Some areas of epithelial cells disintegrated and sloughed in the gut lumen. The basal part of epithelial cells were disintegrated and separated from the muscle. Injected adult and fed on sesban showed cell disorganization and lysis in some areas cell boundaries disappeared (Fig. 5B). Regarding to infected adults fed on clover, detachment of microvilli from epithelial cells and degeneration of basement membrane appeared in some areas epithelial cells disorganized, slightly vaculated and cell boundaries disappeared (fig. 6B).

\section{Discussion}

Alteration of herbivorous insect immunity by the host plant could be of major importance as it should determine the ability of natural enemies to control the herbivorous insect population and therefore the damage to the host plant (Lampert, 2012).

The present study demonstrated the impact of four plants with different nutritional value on the immune response of $S$. gregaria to Bti infection. According to Barakat et al. (2013), the tested plants grass, sorghum, sesaban and clover are differed from each other in the nutritional value. This variation was directly propotional to the ratio of protein to carbohydrate content of the plants. protein to carbohydrate (P: C) ratio in clover was the highest (1:3.3) followed by sesbsn then sorghum and the lowest ratio was in grass (1:3.7).

Circulating haemocytes have important functions on the immune system, metabolism, and detoxification, and play a crucial role in the defense of xenobiotics or microbial infection (Zhu et al., 2012). This work proceeded to the impact of host plant- pathogen interaction on differential and total haemocyte count of adult locust before and after injection with Bti. Four types of haemocytes were found in locust fed on each experimental plant (PRs, PLs, GRs and OEs).

The present results investigated that normal locusts fed on clover (high protein diet) had the highest percentage of PLs (55.80\%) and the highest percentage of GRs (30.30\%) was found in normal locusts fed on sorghum (high carbohydrate diet). Szymaś and Jędruszuk, 2003 stated that GRs cells may act as storage cells in insect. Idowu and Sonde (2003) also found that Pls numbers are the most in cassava (high protein diet) fed grasshopper and are the lowest in acalypha (low protein diet) fed grasshopper while GRs numbers are the highest in grasshopper fed highest carbohydrate diet. Further,

Following bacterial-injection into the locusts, the PLs increased and the GRs decreased at postinjection in all treatments than control insects. The increase in PLs was attributed to the release of sessile haemocytes after infection, and the decrease in GRs may be attributed to their involvement in phagocytosis and nodule formation. This idea is supported by the examinations of Anandakumar and Michael (2011) on silk worm larvae infected with Bti. Hillyer et al. (2005) stated that the reduction of phagocytic GR cells may affect the ability of insects to clear high infection levels. In addition, insects fed with protein might invest more resources in certain types of haemocytes (e.g. Grs or PLs) at the expense of others types (Alaux et al., 2010). With respect to the absence of PRs in insects fed on sorghum, sesban or clover, Mori (1979) suggested that the decrease of PRs after injection may be explained with the transformation of PRs (stem cells) into PLs and GRs which are needed in phagocytosis and nodule formation. From our observation we suggested that toxins secreted by injected bacteria cause lysis of haemocytes or induce programmed cell death. Andrade et al. (2010) suggested that these cells are not directly involved in the processes of immunological defense against the bacterial infection or that its participation occurs in the posterior stages of immunological responses.

The low values presented by OEs in infected and non-infected desert locust in this study was confirmed by Silva et al. (2002) who reported the absence of quantitative alterations of OE in response to pathogens in the haemocoel of Anastrepha oblique larvae. It is known that the OE cells are involved in the production of prophenoloxidase, an enzyme that actively participates in the mechanisms of defense in insects (Lavine and Strand, 2002). However, in the period of infection used, we could not detect alteration in the frequency of the OEs in infected S. gregaria adults compared to non-infected adults, suggesting that these cells are not directly involved in the processes of immunological defense against the bacterial infection or that its participation occurs in the posterior stages of immunological responses (Andrade et al., 2010). 
In this study, we provided experimental evidence for a link between nutrition and haemocyte concentration in desert locust. Locusts fed on high protein diet (clover) had the highest haemocyte count while those fed on low protein diet (grass) had the lowest haemocyte count. These results suggest that the abundance and diversity of environmental resources can have a direct impact on insect immune system. Higher haemocyte concentrations are expected to be associated with high protein diet and higher resistance to disease. Natural proteinaceous food is an important factor in the function of the cellular system of insect haemolymph where a lack of protein in the diet causes considerable changes in the function and structure of the cellular system of the haemolymph (Szymaś and Jędruszuk, 2003). One possibility is that the high food quality stimulates increased proliferation of one or more haemocytes types (Castillo et al., 2006).

Generally, the THC is positively correlated with the rate of phagocytosis and nodule formation. The total number of haemocytes in haemolymph is likely to reflect the capability of immune system to deal with pathogens or chemical molecules (Mo`men, 2010). Similar observations were also reported by Anandakumar and Michael (2011) who noticed that about $15.3 \%$ of the total haemocytes were decreased after bacterial infection in silk worm larvae when compared to non-infected larvae. They clarified that the decrease in total THCs infected worm with Bacillus was due to the depletion of prohaemocytes, which accounts for most of the lowered total counts compared to the normal. Banville et al. (2012) observed that the higher level of haemocytes and antimicrobial peptide expression in unstarved Galleria mellonella larvae leads to significantly greater ability to limit or remove the pathogen than starved insects.

In this study the kind of food that desert locust consumes has a clear impact on the structure of the midgut. We observed thicker microvilli in locusts fed on clover, sesban or sorghum whereas thinner microvilli were found in those fed on grass. Like these differences are observed by Terra et al. (2006) who stated that the densities of isolated plasma membranes of insect cells depend essentially on their protein contents. Szymaś and Przybył (2007) noticed that the midgut epithelium of worker bees fed sugar syrup didn't revealed numerous peritrophic membrane but those fed the pollen substitute showed a distinct peritrophic membrane. Further, Aljedani et al. (2010) found clear impact to the kind of food that bee consumes on the structure of the midgut. As the tissues of the queen honey bee were more advanced than that of the bee workers.

Many pathogens have developed specific mechanisms such as production of toxins that physically disrupt the gut epithelium (Kaur and Ganguly, 2003). The results of our study demonstrated that injection of Bti in desert locust adult lead to damage in the midgut. The experimental plants consumed prior to challenge with bacterial injection has been shown to modify susceptibility of desert locust to the diseases. The well-nourished (clover, sesban and sorghum) locusts decreased performance of Bti than fed grass by less deformation in midgut structure. This confirmed by Plymale et al. (2008) who found that Heliothis virescens larvae fed on cotton had more tough peritrophic membrane than those fed on artificial diet. Moreover, the gut epithelium and its associated microorganisms provide an important barrier that serves both to prevent invasion by potential pathogens and limit the elicitation of host responses to the resident microbiota (Artis, 2008). Abnormality of this barrier, which can occur as a result of alterations of the normal gut environment or damage of host immune defenses may lead to pathological condition (Stecher and Hardt, 2008).

Finally, we can concluded that, the host plants with high nutritional quality; clover, surgham or sesaban; have a higher immune potential than those with poor quality (grass). As the results showed that, the normal or control and $B t i$ infected adults had considerable variation in the differential and total haemocyt counts according the host plant. Furthermore, the host plant has clear impact on the structure of the midgut and its response to Bti. Subsequently, the host plant could be a major factor that affect on the response of herbivorous insects to the pathogens.

\section{References}

[1]. Alaux, C., F. Ducloz, D. Crauser and Y. Le Conte 2010. Diet effects on honeybee immunocompetence. Biol. Lett., 6 (4): $562-565$.

[2]. Aljedani, D. M., A. A. Al-Ghamdi and R. M. Almehmadi 2010. Comparative study in midgut histological structure of queen and worker Yemeni honey bees Apis mellifera jemenitica (Hymenoptera: Apidae) in pupae and adult stages under natural nutrition. The Assiut Univ. Bull. Environ. Res., 13 (2): 63- 76.

[3]. Anandakumar, M.D. and A.S. Michael 2011. Haematology and haemochemistry of silkworm, Bombyx Mori L. infected with Bacillus thuringiensis. Int. J. Environ. Sci., 2 (2): $451-457$.

[4]. Andrade, F. G.; M. C. C Negreiro; S. M. Levy; I. C. B. Fonseca; F. Moscardi and A. M. F. Falleiros 2010. Hemocyte quantitative changes in Anticarsia gemmatalis (Lepidoptera: Noctuidae) larvae infected by AgMNPV. Braz. Arch. Biol. and Technol., 53 (2): 279-284.

[5]. Artis, D. 2008. Epithelial-cell recognition of commensal bacteria and maintenance of immune homeostasis in the gut. Nat. Rev. Immun., 8: 411-420.

[6]. Barakat, M.S., M. O. El-Monairy, N. M. El-barky; M. F. Abd-EL Aziz and H. F. Abd-El khalek. 2013. Effect of diet on the haemolymph protein profile of the desert locust, Schistocerca gregaria Forskal (Orthoptera: Acrididae) and susceptibility of adult to Bacillus thuringiensis israelensis. Afr. J. Biol. Sci., 9(1): 81-93.

[7]. Banville, N.; N. Browne and K. Kavanagh, 2012. Effect of nutrient deprivation on the susceptibility of Galleria mellonella larvae to infection. Virulence, 3(6): 497-503.

[8]. Disbrey, B. D. and J. H. Rack 1970. Histological laboratory methods. E. \&S. Livingstone, Edinburgh and London.

[9]. Gillespie J. P.; M. R. Kanost and T. Trenczek 1997. Biological mediators of insect immunity. Ann. Rev. Entomol. 42: 611-643. 
[10]. Hillyer, J. F., S. L. Schmidt, J. F. Fuchs, J. P. Boyle and B. M. Christensen 2005. Age-associated mortality in immune challenged mosquitoes (Aedes aegypti ) correlates with a decrease in haemocyte numbers. Cell. Microbiol. 7: 39-51.

[11]. Hoffmann JA. 1969. Etude des cellules sanguines (hemocytes) chez Locusta migratoria L (Orthoptere). Mem. These, Fac. Sci. Strasbourg

[12]. Hoffmann, D. 1980. Induction of antibacterial activity in the blood of the migratory locust, Locusta migratoria L. J. Insect Physiol., 26: 539-549.

[13]. Huxham, I. M., K. D. Z. Samuel, J. B. Heale and N. J. MacCorkindale 1989. In vivo and in vitro assays for pathogenicity of wild type and mutant strains of Metarhizium anisopliae for three insect species. J. Invertebr. Pathol., 53: 143-151.

[14]. Idowu, A. B. and O.A. Sonde, 2003. The contribution of food plants to the growth, development and fecundity of Zonocerus variegates. Afr. J. Biotechnol, 2 (10): 350- 355.

[15]. Jones, J. C. 1962. Current concepts concerning insect haemocytes. Am. Zool., 2: 209- 246.

[16]. Kaur, T. and Ganguly, N. K. 2003. Modulation of gut physiology through enteric toxins. Mol. Cell Bioch., 253:15-19.

[17]. Lampert. E. 2012. Influences of Plant Traits on Immune Responses of Specialist and Generalist Herbivores. Insects, 3: 573-592; doi:10.3390/insects3020573

[18]. Mo'men, S.A.A. 2010. The role of prophenoloxidase activation system in cellular defense mechanisms in the haemolymph of the desert locust, Schistocerca gregaria. Msc thesis in Ain Shams University.

[19]. Mori, H. 1979. Embryonic haemocytes. In: Origin and development in insects haemocytes. (Eds., Gupta, A.P.). pp. 3-27. Cambridge, Camridge university press.

[20]. Plymale, R., M. J. Grove, N. Ostiguy and K. Hoover 2008. Plant-mediated alteration of the peritrophic matrix and baculovirus infection in lepidopteran larvae. J. Insect Physiol., 54: 737-749.

[21]. Shikano, I., J. D. Ericsson, J. S. Cory and J. H. Myers 2010. Indirect plant-mediated effects on insect immunity and disease resistance in a tritrophic system. Basic Appl. Ecol. 11:15-22.

[22]. Stecher, B. and W.D. Hardt 2008. The role of microbiota in infectious disease. Trends Microbiol, 16: 107-114.

[23]. Strand, M. R. 2008 The insect cellular immune response. Insect Sci., 15:1-14.

[24]. Szymaś B. and A. Jędruszuk 2003. The influence of different diets on haemocytes of adult worker honey bees, Apis mellifera. Apidologie, 34: 97-102.

[25]. Szymaś, B. and A. Przybył 2007. Midgut histological picture of the honey bee (Apis mellifera L.) following consumption of substitute feeds supplemented with feed additives. Nauka Przyroda Technol., 1: 39-48.

[26]. Terra, W., R. H. Costa, and C. Ferreira 2006. Plasma membranes from insect midgut cells. Ann. Braz. Acad. Sci., 78 (2): $255-$ 269.

[27]. Vogelweith, F., D.Thiery ; B. Quagliett, Y. Moret and J. Moreau 2011. Host plant variation plastically impacts different traits of the immune system of a phytophagous insect. Funct. Eco., 25: 1241-1247.

[28]. Zhu, Q., Y. He, J. Yao, Y. Liu, L. Tao, and Q. Huang, 2012. Effects of sublethal concentrations of the chitin synthesis inhibitor, hexaflumuron, on the development and hemolymph physiology of the cutworm, Spodoptera litura. J. Insect Sci., 12 (27): 1-13.

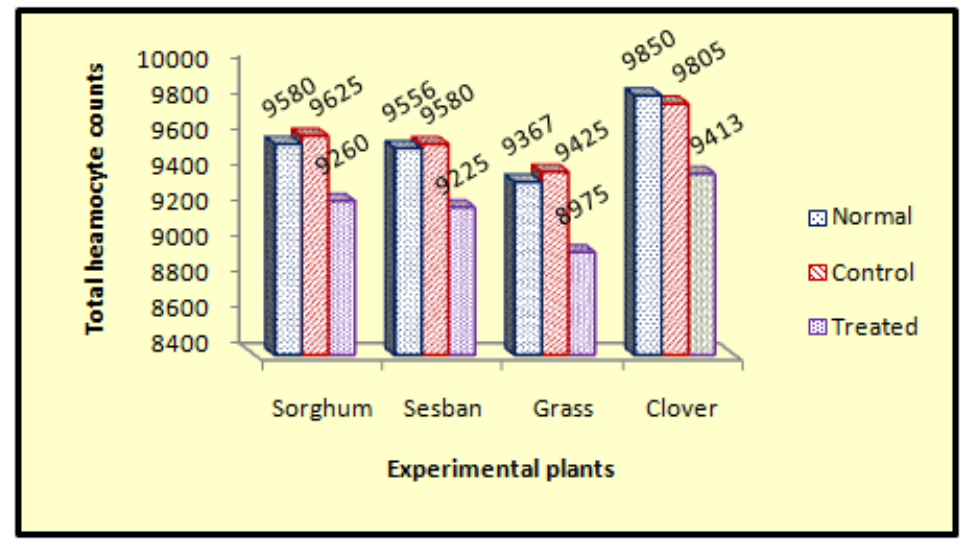

Fig. 1: Effects of $\mathrm{LD}_{20}$ of Bti on total haemocyte counts of S. gregaria adults (2-4 days old) fed on experimental plants at $48 \mathrm{hr}$ post-injection.

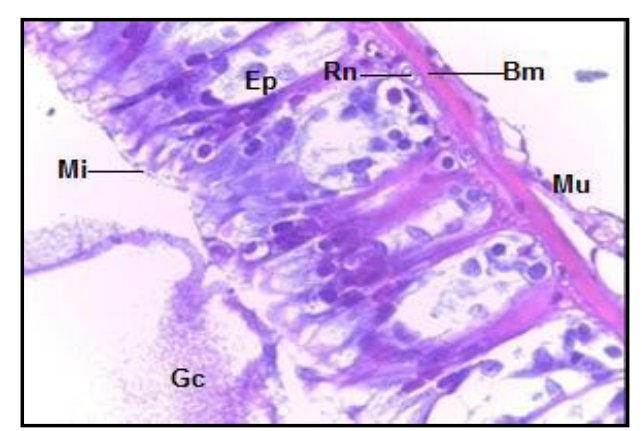

A

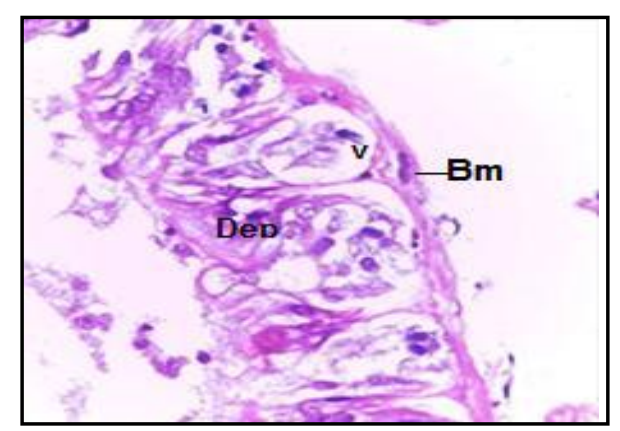

B

Fig. 2: Transversal section in normal (A) and infected Bti (B) S. gregaria adult (2-4 days old) midgut fed on grass $(X-400)$ 


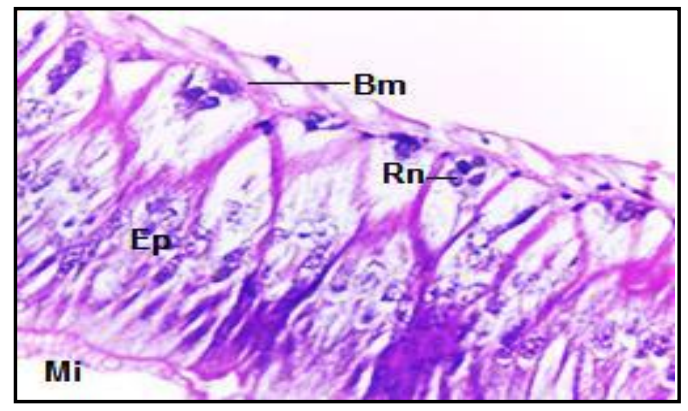

A

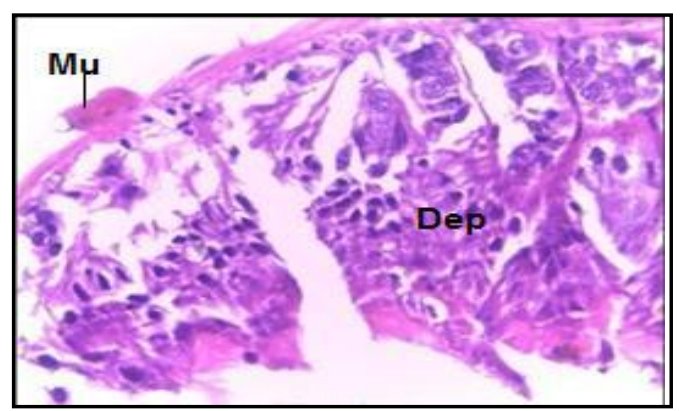

B

Fig. 3: Transversal section in normal (A) and infected Bti (B) S. gregaria adult (2-4 days old) midgut fed on sorghum (X-400).

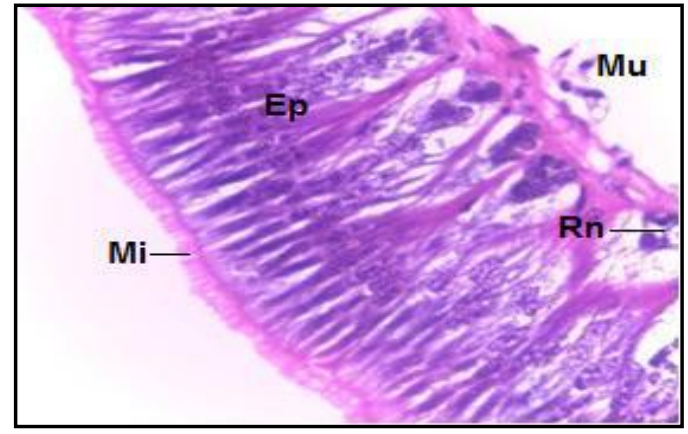

A

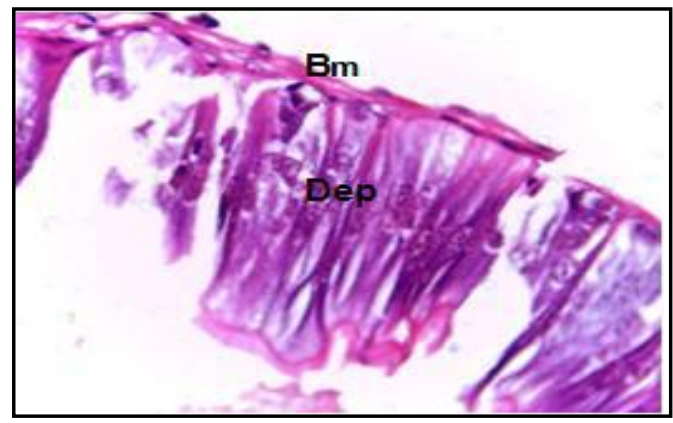

B

Fig. 4: Transversal section in normal (A) and infected Bti (B) S. gregaria adult (2-4 days old) midgut fed on sesaban (X-400).
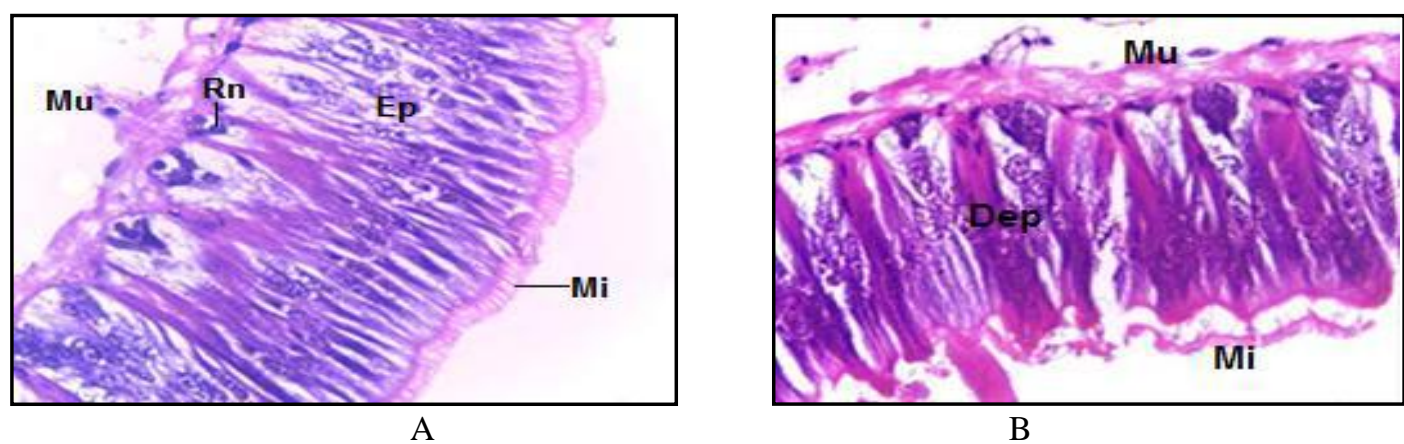

Fig. 5: Transversal section in normal (A) and infected Bti (B) S. gregaria adult (2-4 days old) midgut fed on clover (X-400).

\begin{tabular}{|c|c|c|c|c|c|c|c|c|c|c|c|c|}
\hline \multirow{2}{*}{$\begin{array}{c}\text { Experimental } \\
\text { plants }\end{array}$} & \multicolumn{9}{|c|}{ Haemocyte type \%" } \\
\cline { 2 - 14 } & \multicolumn{2}{|c|}{ Prohaemocytes } & \multicolumn{3}{|c|}{ Plasmatocytes } & \multicolumn{2}{|c|}{ Granulocytes } & \multicolumn{3}{c|}{ 0enocytoids } \\
\cline { 2 - 13 } & Normal & Control & Treated & Normal & Control & Treated & Normal & Control & Treated & Normal & Control & Treated \\
\hline Sorghum & 14.80 & 13.90 & 00.00 & 51.10 & 50.60 & 69.00 & 30.30 & 31.00 & 25.90 & 3.80 & 4.50 & 5.10 \\
\hline Sesban & 13.60 & 15.90 & 00.00 & 52.70 & 52.20 & 70.50 & 27.50 & 27.30 & 25.50 & 5.20 & 4.60 & 4.00 \\
\hline Grass & 15.80 & 14.50 & 3.20 & 52.20 & 53.80 & 65.90 & 26.70 & 25.90 & 24.00 & 5.30 & 5.80 & 6.90 \\
\hline Clover & 12.90 & 15.40 & 00.00 & 55.80 & 56.40 & 75.10 & 29.60 & 30.80 & 22.80 & 1.70 & 1.50 & 2.10 \\
\hline
\end{tabular}

on $=10$ replicates

Nomal adults: un-injected, control: water-injected, treated bacteria-injected 